\title{
PESQUISA COM FORMAÇÃO: construir (auto)conhecimento sobre a formação de professores formadores
}

\author{
Isabel Cristina Fernandes Ferreira \\ Rita Esther Ferreira de Luna \\ Michelle de Freitas Bissoli
}

\section{Resumo}

Este artigo resulta dos estudos teóricos preliminares de pesquisas de doutorado em andamento que se utilizaram da proposta teórico-metodológica aqui denominada pesquisa com formação. Fundamenta-se em uma pesquisa bibliográfica anterior ao desenvolvimento da ida a campo. Procedemos à análise e sistematização dos materiais selecionados, que passaram por posterior fichamento e catalogação. A análise fundamenta-se nos pressupostos da Teoria Histórico-Cultural e no Materialismo Histórico-Dialético e demonstra que as relações entre pesquisa e formação tornam o processo investigativo uma atividade intelectual que constrói o conhecimento acerca da formação do formador, objeto das pesquisas, ao mesmo tempo em que transforma aqueles que dela participam como sujeitos: pesquisador e pesquisados.

Palavras-chave: pesquisa com formação; formação de professores; materialismo histórico-dialético.

TRAINING RESEARCH:

building (self)knowledge about training teacher trainers

\begin{abstract}
This article results from preliminary theoretical studies of ongoing doctorate degree research that used the theoretical-methodological proposal called research with training. It is based on a bibliographic research prior to the development of the field trip. We proceeded to the analysis and systematization of the selected materials, which were later filed and cataloged. The analysis is based on the assumptions of the HistoricalCultural Theory and the Historical-Dialectical Materialism and demonstrates that the relations between research and formation make the investigative process an intellectual activity that builds knowledge about the formation of the trainer, object of the research, at the same time, it transforms those who participate in it as subjects: researcher and researched ones.
\end{abstract}

Keywords: research with training; teacher training; historical-dialectical materialism.

\section{INVESTIGACIÓN COM FORMACIÓN: construir (auto)conocimiento sobre la formación de profesores formadores}

Resumen

Este artículo es el resultado de estudios teóricos preliminares de investigación doctoral en curso que utilizaron la propuesta teórico-metodológica llamada investigación con capacitación. Se basa en una investigación bibliográfica previa al desarrollo de la excursión. Se procedió al análisis y sistematización de los materiales seleccionados, que luego se archivaron y catalogaron. El análisis se basa en los supuestos de la teoría histórico-cultural y el materialismo histórico-dialéctico y demuestra que las relaciones entre investigación y formación hacen del proceso de investigación una actividad intelectual que construye el conocimiento sobre la formación del formador, objeto de la investigación, al mismo tiempo que transforma a quienes participan en él como sujetos: investigador e investigado.

Palabras clave: investigación con formación; formación de profesores; materialismo histórico-dialéctico. 


\section{INTRODUÇÃO: COMEÇAR POR ONDE NO CAMINHO DA PESQUISA?}

Tratar da relação entre pesquisa e formação significa buscar caminhos que contribuam para a construção do conhecimento em educação (trans)formando os sujeitos que as constituem. Não se trata de uma temática nova. A relação entre pesquisa e formação de professores(as) passou a integrar o debate no meio educacional a partir da segunda metade do século XX, no mundo todo. Buscando pontos de intersecção entre pesquisa e formação e voltados para a intervenção nas escolas a partir das iniciativas dos(as) professores(as) que nelas atuavam para transformar sua realidade, diferentes pensadores(as) investiram na construção desse caminho (ANDRÉ, 2002; BUENO, 2002; RAUSCH, 2012).

O potencial formativo da pesquisa tem sido demonstrado por diferentes abordagens, alinhadas ao paradigma qualitativo: a pesquisa-ação (THIOLLENT, 2007); a pesquisa colaborativa (GARRIDO; PIMENTA; MOURA, 2000; MOURA; FERREIRA, 2004); a pesquisa-ação críticocolaborativa (PIMENTA, 2006); a pesquisa participante (BRANDÃO, 1990; NORONHA, 2000); a pesquisa coletiva (ALVARADO PRADA, 1997), guardadas suas especificidades metodológicas. E é reconhecendo a força e o potencial da articulação entre pesquisa e formação que objetivamos, com esse estudo, apresentar reflexões que compõem nossas pesquisas de doutorado em andamento e que se articulam a um grupo de pesquisa maior, cujos trabalhos são desenvolvidos sob a perspectiva Histórico-Cultural. Isso também justifica nossa opção por buscar superar por incorporação as contribuições do paradigma qualitativo da pesquisa, buscando construir nossas investigações segundo os princípios do Materialismo Histórico-Dialético, que "[...] tem a prática social como referência fundante da construção do conhecimento, nela residindo os seus critérios de validação" (MARTINS, 2015, p. 40).

Buscamos, nesse texto, evidenciar o potencial emancipatório e crítico que a articulação entre a pesquisa e a formação de professores(as) pode e deve assumir. Partimos do pressuposto epistemológico que localiza os sujeitos participantes da pesquisa como históricos, co-construtores de um processo que os forma, nos forma e dá forma ao conhecimento em educação. E, para tanto, valoriza o diálogo, a reflexão, a ressignificação e a tomada de consciência a respeito da temática sobre a qual o conhecimento é construído.

Nossas reflexões sustentam-se no estudo bibliográfico efetivado em busca de uma alternativa teórico-metodológica coerente com os pressupostos da Teoria Histórico-Cultural e, portanto, com os princípios do Materialismo Histórico-Dialético (DELARI JR., 2015; KOSIK, 2002; MARTINS, 2015; NAGEL, 2015), tendo nosso olhar direcionado para o objeto das pesquisas de doutorado de duas das autoras desse texto, orientadas pela terceira: a formação do professor formador de outros professores, na Universidade e em instituições vinculadas às Secretarias Municipais de Educação.

Dessa forma, nesse artigo, trataremos, especificamente, sobre as concepções que fazem convergir pesquisa e formação e que podem gerar aproximações entre os sujeitos que pesquisam e os que são pesquisados, na perspectiva de constituir o que aqui denominamos pesquisa com formação, um espaço-tempo organizado intencionalmente para oportunizar vivências formativas emancipadoras que permitam produzir conhecimentos e autoconhecimento sobre a formação do(a) professor(a) formador(a) de outros(as) professores(as), tema apontado por Zeichner (2009) e corroborado por Diniz-Pereira (2013), como prioridade absoluta na constituição de uma agenda para a pesquisa sobre formação de professores. 


\section{A PESQUISA COM FORMAÇÃO: DESAFIOS E POSSIBILIDADES}

Sabemos que a intencionalidade da pesquisa e a ação investigativa estão estreitamente interligadas, conectando-se por elos teóricos e práticos na construção do método (VIGOTSKI, 2018). Assim, para alcançarmos o objetivo de uma pesquisa, precisamos estar cientes do valor de estabelecer nexos entre os procedimentos por intermédio dos quais se ascende ao conhecimento científico e os seus fins e, ainda, das dificuldades a serem enfrentadas para a apreensão do real, avançando da aparência à essência dos fenômenos. Portanto, "[...] é preciso caminhar das representações primárias e das significações consensuais, em sua imediatez sensível, em direção à descoberta das múltiplas determinações ontológicas do real” (MARTINS, 2015, p. 36-37).

Enxergar a realidade a ser investigada, dialeticamente construída diante dos e pelos pesquisadores e sujeitos da pesquisa, a partir da postura participativa, problematizadora, crítica e responsável pressupõe as noções de totalidade, de movimento e contradição. Nessa perspectiva, para que possamos conhecer a coisa em si (a formação do(a) professor(a) formador(a) de outros(as) professores(as), especificamente), isto é, a essência do objeto ou do fenômeno da pesquisa, precisamos ter clareza de que é preciso buscar sistematicamente a sua estrutura, a sua natureza e os seus múltiplos determinantes. Entretanto, nenhum desses aspectos se mostra imediatamente. Por isso, a realidade investigada requer ser decomposta em suas unidades constitutivas (VIGOTSKI, 2018) e não pode ser confundida com os fenômenos que se manifestam de modo mais imediato. Isso significa buscar, na formação dos(as) professores(as) formadores(as) de outros(as) professores(as) - objeto das pesquisas - e nos procedimentos construídos para a produção de dados, aqueles elementos que trazem consigo todas as partes do todo investigado, sem fragmentálos: os sentidos que os sujeitos, localizados historicamente, atribuem ao trabalho de formar outros(as) professores(as), ao como o fazem e ao por que o fazem e, ainda, se, pela mediação da pesquisa, os transformam e como os transformam.

É preciso construir caminhos para acessar esses sentidos e tais caminhos não estão prontos a priori. Precisam ser forjados com e pelos sujeitos, produzindo situações que permitam deixar vir à tona conhecimentos, afetos, necessidades presentes na biografia de cada um e mediados por condições concretas de existência. A pesquisa assume, assim, sua vocação formativa e transformadora,

[...] ao reconhecer na origem da teoria do conhecimento um "nós", um "cogitamos", e não um "cogito" [...] [partindo] de uma situação objetiva, de um dado concreto, de um fato social, que diretamente fixa e qualifica a posição de cada indivíduo singular num processo histórico [...]. (PINTO, 1969, p. 16).

No processo da pesquisa temos, pois, o desafio de superar a pseudoconcreticidade, para a qual os fenômenos são concebidos como se não fossem produzidos historicamente pelo homem a partir do seu trabalho, e a práxis fetichizada - fragmentada e naturalizada -, para, assim, atingir a concreticidade ou a compreensão da realidade como totalidade concreta (KOSIK, 2002). Somente assim poderemos conhecer o(a) professor(a) formador(a) como sujeito real de um mundo real e superar a naturalização da alienação, da precarização e da desumanização em seus processos formativos e na sua atuação profissional.

Assim como a pesquisa é histórica, datada e situada, o(a) pesquisador(a) e o sujeito da pesquisa também o são e desenvolvem suas atividades no trato com a natureza, com a sociedade e com os outros homens, a partir de determinados objetivos, necessidades e interesses em meio a um conjunto de relações sociais. O ser humano, neste caso, o(a) professor(a) formador(a), no materialismo histórico-dialético: 
[...] é tal qual se produz. [...] Não existe uma essência, um conteúdo programado, uma humanidade que anteceda a própria atividade do homem. Ele é o trabalho, e é o trabalho que lhe confere qualquer distinção, qualquer característica, qualquer dignidade. Sua história é a história da produção dos meios para satisfação de suas necessidades (necessidades sempre criadas pelo próprio trabalho obrigatório para ficar vivo). (NAGEL, 2015, p. 23)

Nessa perspectiva, a pesquisa com formação, embasada no Materialismo Histórico-Dialético, busca conhecer o movimento, identificar quais são as condições de existência de uma determinada formação social - e de um grupo específico, no caso, de professores(as) formadores(as) no interior dessa formação - e suas contradições, na perspectiva de gerar necessidades que coloquem os sujeitos da pesquisa em desenvolvimento, intencionalmente.

Não é possível, pois, conhecer o trabalho do(a) professor(a) formador(a) separado do contex to histórico, do exercício da sua profissão e da sua formação, pois cada atitude e depoimento têm sentido apenas quando estão vinculados à realidade e à pessoa que os gera. O conhecimento, nesse entendimento, exige a consideração das condições concretas e contraditórias da formação e da docência de cada sujeito. Assim, o percurso da pesquisa requer que reflitamos, continuamente, sobre essa realidade e sobre como as necessidades dos(as) professores(as) são criadas e se modificam, a partir de um suporte teórico-científico que favoreça a crítica e a tomada de consciência, para dar voz e vez aos sujeitos que, na pesquisa, tecem um conhecimento a respeito de si e do seu trabalho, entretecendo-se.

Nesse contexto, a partir das reflexões e análises sobre os pressupostos do Materialismo Histórico-Dialético, a pesquisa com formação surge para nós como uma possibilidade, um caminho teórico-metodológico. Porque o pensamento dialético exige um profundo senso crítico e a unidade entre a análise teórica e a prática que lhe é correspondente, entendemos que a pesquisa se coloca como atividade teórico-prática de construção de um conhecimento e, portanto, como trabalho intelectual de todos(as) os(as) que nela estão envolvidos. Assim, à medida que essa atividade transforma a natureza daquilo que se sabe sobre formação de professores(as) formadores(as), constituindo saberes acerca desse fenômeno, os(as) transforma a si mesmos(as). Não há pesquisa sem formação daqueles(as) que pesquisam e participam desse processo, embora com funções distintas - a daqueles(as) que são convidados(as) a refletir sobre sua própria formação e a nossa, aqueles(as) que têm como reponsabilidade mediar os processos e sistematizar o conhecimento produzido (PASQUALINI, 2015).

Decorre daí o desafio incessante, para nós, de pensarmos dialeticamente. Sem separar sujeito e objeto, teoria e prática, entender a formação e o trabalho do(a) professor(a) formador(a) requer conhecer, a partir das vozes dos sujeitos participantes da pesquisa, as condições concretas de sua atividade, do se tornar humano, superando falsas dicotomias. Com base nisso, temos a intenção de produzir o que queremos pesquisar: não nos basta olhar a pesquisa a partir de fora; pelo contrário, queremos fazer parte, dialogar, porque partimos dos pressupostos de que é no diálogo que se produzem as consciências (VOLÓCHINOV, 2017) e de que "[...] a pesquisa de abordagem histórico-cultural se constitui como um espaço educativo no qual se desenvolvem diferentes processos de comunicação" (FREITAS, 2009, p. 2). Deparamo-nos, então, com nosso próximo desafio: construir um conjunto de procedimentos que, a partir da base epistemológica já apresentada, nos faça transitar nesse duplo lugar - de sujeitos que pesquisam e que constroem conhecimentos, sendo por eles construídos, privilegiando o processo formativo de todos(as) os(as) envolvidos(as).

Para ampliar e refinar nosso olhar sobre o que aqui concebemos como pesquisa com formação, partimos, inicialmente, da conceituação apresentada por Josso (2004, p. 41): a pesquisa-formação, entendendo-a como uma simultaneidade entre sujeito e objeto. Nessa perspectiva, "Os 
participantes da pesquisa, aprendentes, constroem suas capacidades de escuta de si mesmo e de partilha, atentos às considerações sobre formação, tecidas no trabalho de narrar suas experiências e seus processos formativos". Como é possível notar, Josso (2004) assevera que o(a) pesquisador(a)-formador(a) não se distancia, mas se embrenha no universo da pesquisa, numa busca constante de (re)construir sentidos e significados, a fim de formar e formar-se, transformar e transformar-se ao longo do processo.

Essa forma de pensar a pesquisa carrega a dimensão formativa como elemento norteador, tornando-a prenhe de possibilidades, essencial na investigação. Os caminhos da pesquisaformação, assim, nos permitem romper com o distanciamento entre pesquisador(a) que investiga e sujeitos investigados, fazendo com que tanto um quanto o outro sejam responsáveis pela produção de conhecimentos. Entretanto, sabemos que as narrativas oriundas do processo de pesquisa-formação não podem dar conta de tudo o que rodeia e perpassa a pesquisa, visto que:

[...] a narrativa de vida não tem em si poder transformador, mas, em compensação, a metodologia de trabalho sobre a narrativa de vida pode ser a oportunidade de uma transformação, segundo a natureza das tomadas de consciência que aí são feitas e o grau de abertura à experiência das pessoas envolvidas no processo. (JOSSO, 2004, p. 153).

Nesse sentido, começamos a refletir sobre um caminho teórico-metodológico que pudesse superar o da pesquisa-formação enunciada por Josso, já que queríamos imprimir um jeito de caminhar particular, tendo em vista nossas escolhas epistemológicas e, também, o nosso envolvimento com formação continuada de professores em nosso percurso profissional. Dessa forma, optamos por desenvolver o que chamamos de pesquisa com formação. E, embora tenhamos nas narrativas produzidas pelos sujeitos também um elemento essencial de análise, colocamo-las no interior de um processo coletivo, em que o diálogo se apresenta como a fonte de sentidos sobre a qual nos debruçamos. Passamos a denominá-las enunciações, próprias da prática discursiva que nos constitui as consciências, sob a perspectiva de Volóchinov (2017). Entendemos que, se por um lado, os enunciados expressam singularidades, também nos permitem perceber a particularidade em que os sujeitos atuam - as condições concretas em que seu trabalho se desenvolve - nos possibilitando perceber em que medida essa particularidade autoriza ou obstaculiza a aproximação dos sujeitos com o trabalho como atividade de desenvolvimento humano de si e de outrem, com a universalidade (OLIVEIRA, 2005; PASQUALINI, MARTINS, 2015).

Essa é, pois, não só uma migração conceitual, mas, também, um deslocamento do lugar em que $\mathrm{o}(\mathrm{a})$ pesquisador(a)-formador(a) se coloca na pesquisa: de alguém que analisa para alguém que produz sentidos, no e pelo diálogo com os(as) participantes do processo. E sobre o que dialogam os sujeitos? Colocam sob perspectiva o que significa ser formadores de professores em cada locus e, sobretudo, na sociedade capitalista, hoje; como a realidade material permite que a relação com o trabalho de formar outros(as) professores(as) seja mais livre e universal ou como impede essa liberdade e a aproximação com aquilo que se coloca como o ideal da formação.

Tal prospecção aproxima o ato de pesquisar do ato de contribuir para a emancipação humana e profissional dos sujeitos. Pela mediação dos encontros dialogais, das práticas discursivas entre pesquisador(a) e sujeitos surgem oportunidades de co-construir o conhecimento sobre si mesmos e a realidade e a possibilidade de tornar a atividade teórica, durante a formação - e a atuação profissional -, a base orientadora da reflexão crítica e da prática transformadora da realidade. Entendemos que o conhecimento verdadeiro "[...] implica uma reprodução espiritual da realidade, reprodução que não é um reflexo inerte, mas sim, um processo alvo que Marx definiu como ascensão do abstrato ao concreto em e pelo pensamento" (SÁNCHEZ VÁZQUEZ, 2011, p. 244). 
Trata-se de atuar, na pesquisa, em função da formação do pensamento reflexivo, ou da reflexão como função psíquica superior - de natureza social (VYGOTSKI, 2012) - ou de mediar um processo metacognitivo que permite ao sujeito colocar em ação seu pensamento, sua volição, seus afetos, de forma pessoal e intransferível.

A conceituação da prática reflexiva como uma atividade mediada por ferramentas para que os professores desenvolvam a reflexão como uma função psicológica superior permite projetar programas de formação de professores e atividades que conduzam ao desenvolvimento dos professores como aprendizes e pesquisadores de sua prática. (LAMPERT-SHEPEL, 2018, p. 2).

Teoria e prática não são, assim, dicotômicas; formam uma unidade. Unidade essencial à práxis, à crítica, ao conhecimento, à humanização e à docência. Sendo assim, a pesquisa com formação assume o próprio movimento do processo formativo em que tanto pesquisador(a) como professores(as) investigados(as) se colocam em dupla direção. Se são pesquisadores de sua própria formação e prática, buscando transformá-la pela mediação dos elementos conceituais que vão sendo apresentados e discutidos no decorrer da pesquisa, são, também, sujeitos dessa pesquisa, dando-se a conhecer e a autoconhecer-se.

Se apenas a teoria não transforma a realidade, ela é essencial para subsidiar a tomada de consciência pelos sujeitos e fundamentar as ações que objetivam tal transformação. A atividade teórica pode promover a tomada de consciência sobre o desenvolvimento intencional de uma atividade prática já existente, mas pode, igualmente, conduzir ao desenvolvimento de uma prática que ainda não existe ou que é ainda inicial. A teoria apenas será fecunda se estiver em relação com a "[...] realidade que é objeto de sua interpretação e transformação e com a própria atividade prática que é sua fonte inesgotável” (SÁNCHEZ VÁZQUEZ, 2011, p. 258) e critério de verdade.

Desse modo, entendemos que é na práxis que o conhecimento é produzido, permitindo compreender a realidade, pois o movimento de trazer para o diálogo a prática da formação de outros(as) professores(as) e de pensar coletivamente sobre os elementos que a compõem historicamente, na realidade material, suscita, pela mediação de abstrações, a necessidade de conhecer, provocando transformações na e da pesquisa. Tal movimento deve estar assegurado no percurso investigativo, que vai sendo constituído à medida que os diálogos se adensam e direcionam para aquilo que deve ser aprofundado.

As enunciações sobre as vivências ${ }^{1} \operatorname{dos}($ as) professores(as) formadores(as) são utilizadas na pesquisa para promover o conhecimento de si, do outro e do objeto da pesquisa. Mediar os processos reflexivos sobre as vivências que se destacam no campo formativo e no campo da atuação na formação de outros(as) professores(as) é a tarefa precípua do(a) pesquisador(a) que, ao colocar-se nesse lugar, também se forma.

Para Toassa (2009, p. 28), “[...] as vivências não podem ser meramente deduzidas dos atos da pessoa, pois, embora determinando as ações, a relação interior da consciência / personalidade com o meio depende de uma elucidação da perspectiva da própria pessoa" e as práticas discursivas são meios privilegiados de acesso e de tomada de consciência a respeito dessas vivências, constitutivas dos sentidos atribuídos ao ser professor(a) formador(a). Assim, as enunciações como produção autoral, na participação individual e coletiva, trazem a possibilidade da construção do

${ }^{1}$ [...] A vivência é uma unidade na qual, por um lado, de modo indivisível, o meio, aquilo que se vivencia está representado - a vivência sempre se liga àquilo que está localizado fora da pessoa - e, por outro lado, está representado como eu vivencio isso, ou seja, todas as particularidades da personalidade e todas as particularidades do meio são apresentadas na vivência, tanto aquilo que é retirado do meio, todos os elementos que possuem relação com dada personalidade, como aquilo que é retirado da personalidade, todos os traços de seu caráter, traços constitutivos que possuem relação com dado acontecimento. Dessa forma, na vivência, nós sempre lidamos com a união indivisível das particularidades da personalidade e das particularidades da situação representada na vivência (VIGOTSKI, 2010, p. 6). 
conhecimento crítico, da objetivação das reflexões mediadas pelos elementos culturais organizados pelo(a) pesquisador(a) para suscitar os diálogos - textos científicos; pintura; música; poesia; literatura, por exemplo.

Sabemos que cada processo de formação vivido pelos sujeitos, bem como cada história de vida, formação e profissão são únicas. Dão-se num movimento dialético e dialógico, constroem-se a cada dia a partir das interações consigo, com os outros e com o meio, num determinado espaçotempo. É nessa relação com os(as) outros(as) e dessa intersubjetividade dos sujeitos que advém $\mathrm{o}(\mathrm{s})$ conhecimento(s), novos modos de ser e de estar no mundo e, consequentemente, de fazer educação. Tomamos como princípio metodológico o fato de que os encontros intersubjetivos são formadores das capacidades de reflexão individual, atuando sobre a produção de sentidos e envolvendo, portanto, os sujeitos da pesquisa como pessoas completas: cognição, afetos, desejos, visão de si mesmos e do outro se movimentam (VYGOTSKI, 2012).

[...] Só coletivamente se pode buscar e atingir uma noção melhor sobre o conjunto do processo a respeito do qual se busca um conhecimento crítico. Porém, mesmo que necessário, o confronto dialógico não é suficiente para haver objetividade, cabendo também o confronto com a realidade material mediante a "intervenção" prática sobre ela, no interior dela, como componente dela. (DELLARI JR, 2015, p. 53).

Nesse sentido, o diálogo coloca em confronto pontos de vista diferentes, constituídos nas vivências de cada sujeito, o que envolve suas relações com as condições materiais do seu trabalho e seus efeitos na forma de dar sentidos a ele. Conhecer exige confronto. Para compreender o próprio processo formativo e as escolhas no / do caminho, precisamos do diálogo, da escuta, do acolhimento, do conflito e da troca entre os pares, assim como de espaço-tempo para a diferença, para a diversidade e para o respeito. É preciso superar a aceitação incondicional ou resignada do status quo e construir a participação ativa de todos os sujeitos como possibilidade de cada um vir a conhecer a si mesmo, ao outro, à própria profissão e à formação. Nesse sentido, para dar forma à pesquisa com formação, nosso principal procedimento tem sido os grupos de discussão, mediados pelo que Heller (1987) denomina objetivações não-cotidianas, considerando que:

[...] do ponto de vista específico da prática educativa, a consciência crítica implica lançar mão da filosofia, com a qual se desenvolve a contemplação, a reflexão e a crítica; da ciência, pela qual apropria-se de um método para pensar e apreender a prática inserida no contexto mais amplo da realidade objetiva; da arte que, ao apresentar, de forma intensificada, os conflitos existentes na realidade contraditória que todos os homens vivem, educa os órgãos dos sentidos para participar das benesses da cultura e dos problemas do gênero humano; da ética e da moral que ensinam valores essenciais que permitem que o processo de apropriação não se realize em benefício único e exclusivo de alguns homens ou de uma classe e em detrimento do gênero humano. (MELLO, 2000, p. 108).

Durante a pesquisa é mister que todos os envolvidos estejam disponíveis para essa aprendizagem e, também, para ouvir o outro, para expor forças e fragilidades, dar-se conta da parcialidade dos conhecimentos e das práticas, percebendo-se em relação e em construção. Nesse sentido, a postura do(a) pesquisador(a)-formador(a) deve ser consciente, intencional e flexível, já que cabe a ele(a) mediar as práticas discursivas, trazendo elementos para instigar a reflexão e considerar os sentidos que os sujeitos atribuem a suas vivências no trabalho e na própria pesquisa com formação. 


\section{DE UMA FORMAÇÃO EM-SI A UMA FORMAÇÃO PARA-SI NA PESQUISA}

As condições objetivas de existência de cada indivíduo oferecem ou negam possibilidades para a elevação da consciência, por isso a necessidade de ultrapassar, na pesquisa, o nível da aparência e verificar quais são as possibilidades reais para a criação de uma formação de professores(as) formadores(as) que promova a efetivação de uma prática docente que enseja em si a crítica à práxis fetichizada, à alienação e à desumanização. O processo de humanização requer a superação da cotidianidade, a apropriação de objetivações da esfera da vida não-cotidiana (arte, ciência, filosofia, moral e política produzidas histórica e socialmente pelos homens) que possibilitam a elevação das reflexões ao nível da genericidade humana (DUARTE, 2013).

A natureza histórico-social e as mediações políticas, sociais, econômicas e culturais interferem na subjetividade humana. Tomar consciência das próprias vivências e da influência das mesmas na intencionalidade da formação e da profissão docentes impõe uma relação consciente do(a) professor(a) consigo mesmo(a), com o seu próprio condicionamento, com a sua profissão e com a realidade. Como a intencionalidade é decorrente do nível de consciência, não há a possibilidade de se efetivar qualquer ação formativa sem que a mesma seja atravessada pela personalidade do(a) professor(a) formador(a) e que seu desenvolvimento não seja o pressuposto do trabalho (MARTINS, 2001).

A superação de uma formação em-si (própria das esferas cotidianas) a uma formação para-si (formação do indivíduo como alguém que faz de sua vida uma relação consciente com o gênero humano) não se dá imediatamente. É uma construção que vai se fazendo no processo, à medida que nos apropriamos da realidade e que, a partir dela, nos objetivamos. Assim, para além do acesso às esferas não-cotidianas do conhecimento, a tomada de consciência implica também a mudança de postura diante dos problemas da realidade que se nos apresentam a partir de uma interação qualitativa, problematizadora e reflexiva com essa realidade. O que, de fato, coloca em movimento os processos de mudança é o sentido que atribuímos às apropriações e às objetivações que fazemos e a pesquisa com formação busca oportunizar momentos reflexivos que ensejem esse movimento de dar sentidos ao trabalho de formar outros(as) professores(as).

Dessa forma, acreditamos, o processo essencialmente formativo deve ser o foco central de nossas pesquisas se quisermos colaborar com o desenvolvimento pleno do(a) professor(a) formador(a) para que ele(a) tenha condições de vir a ser - condições objetivas e subjetivas favoráveis que o aproximem da universalidade do gênero humano e para que possa, consequentemente, contribuir para a formação humano-genérica de outros(as) professores(as), num movimento que atinja, também e consequentemente, as crianças, jovens e adultos nas escolas. Esse processo poderá contribuir para que cada sujeito possa compreender melhor as contradições existentes na sociedade e no seu trabalho, sem fetichizaçôes, bem como as possibilidades de transformação e de emancipação.

Olhar a realidade de forma mais clara é distanciar-se da alienação em relação ao próprio trabalho. E isso exige, de nós, estar sempre atentos para as teias da realidade que engendram, como se fossem parte da vida cotidiana, espaços que devem constituir-se como específicos da vida nãocotidiana, como a formação de professores e a docência. Assim, se a "[...] alienação está presente quando, por conta de determinadas condições materiais, sociais e econômicas, a estrutura da vida cotidiana incha, hipertrofia-se, e penetra em todas as esferas da vida dos indivíduos" (ROSSLER, 2004, p. 113), cabe construir espaços de questionamento e reflexão e a pesquisa com formação pode constituir uma alternativa para tanto.

Se é pela atividade que formamos nossa consciência e "[...] a atividade dos sujeitos envolvidos no processo educativo pressupõe a sua historicidade, a sua biografia, as relações sociais das quais participam e que portam, em si, a essência humana" (BISSOLI, 2007, p. 357), é certo dizer que a atividade dos sujeitos envolvidos com a pesquisa deve ser de tal forma arraigada em sua 
biografia e nas suas vivências pessoais e profissionais, que tenha condição de gerar necessidade de se questionar sobre os motivos do seu fazer e provocar a tomada de consciência que:

[...] não se reduz a um mundo interno isolado, ao contrário, se está intimamente vinculada à atividade, só pode ser expressão das relações do indivíduo com os outros homens e com o mundo circundante, sendo social por natureza. Mas a passagem do mundo social ao mundo interno, psíquico, não se dá de maneira direta, pois o mundo psíquico não é cópia do mundo social. No trânsito da consciência social para a consciência individual, a linguagem e a atividade coletiva laboral têm papel fundamental. (RIGON; ASBAHR; MORET'TI, 2016, p. 23).

Os sujeitos envolvidos com a pesquisa precisam, portanto, refletir sobre seus fazeres e seus modos de pensar, a princípio, na coletividade, com seus pares e, pela mediação dos conhecimentos não-cotidianos disponibilizados para as reflexões na pesquisa, poderão também transitar na vida não-cotidiana, gerando processos formativos e autoformativos.

Dessa forma, a pesquisa com formação sustenta-se na concepção de que "[...] a consciência pressupõe também ser intransigente em relação a toda vilania que mutile, menospreze e deforme a vida do homem" (RUBINSTEIN, 2017, p. 128). Esse percurso de idas e vindas constantes, tanto para pesquisadores(as) como para professores(as) formadores(as) investigados(as), pode nos dar possibilidades de ascender de uma formação em-si à formação para-si. Para isso, é imprescindível que o(a) pesquisador(a)-formador(a) se entenda como organizador(a) de processos, que tanto podem formar outros(as) como a si próprio(a), aproximando-os(as) a todos(as) do vir a ser.

\section{REFERÊNCIAS}

ALVARADO PRADA, Luis Eduardo. Formação participativa de docentes em serviço. Taubaté: Cabral Editora Universitária Ltda., 1997.

ANDRÉ, Marli. Pesquisa, formação e prática docente. In: ANDRÉ, Marli (org.). O papel da pesquisa na formação e prática dos professores. 2. ed. Campinas: Papirus, 2002. p. 55-70.

BISSOLI, Michelle de Freitas. Por uma educação para-si: algumas reflexões sobre o trabalho pedagógico. Revista Perspectiva, Florianópolis, v. 25, n. 2, jul./dez., 2007, p. 343-368.

BRANDÃO, Carlos Rodrigues (org.). Pesquisa participante. São Paulo: Editora Brasiliense, 1990.

BUENO, Belmira Oliveira. Pesquisa em colaboração na formação contínua de professores. In: BUENO, Belmira Oliveira; CATANI, Denice Barbara; SOUSA, Cynthia Pereira de (org.). A vida e o ofício dos professores. 2. ed. São Paulo: Escrituras Editora, 2002. p. 7-20.

DELARI JR., Acquilles. Questões de método em Vigotski: busca da verdade e caminhos da cognição. In: TULESKI, Silvana Calvo; CHAVES, Marta; LEITE, Hilusca Alves (orgs.). Materialismo Histórico-Dialético como fundamento da Teoria Histórico-Cultural: método e metodologia da pesquisa. Maringá: EDUEM, 2015. p. 43-82.

DINIZ-PEREIRA, Julio Emílio. A construção do campo de pesquisa sobre a formação de professores. Revista da FAEEBA - Educação e contemporaneidade, Salvador, v. 22, n. 40, p. 145-154, jul./dez., 2013.

DUARTE, Newton. A individualidade para si: contribuições a uma teoria histórico-cultural da formação do indivíduo. 3. ed. Campinas: Autores Associados, 2013.

FREITAS, Maria Tereza Assunção. A pesquisa de abordagem histórico-cultural: um espaço educativo de constituição de sujeitos. Revista Teias. Rio de Janeiro, v. 10, n. 19, p. 1-12, 2009. Disponível em: https://www.epublicacoes.uerj.br/index.php/revistateias/article/view/24057/17026. Acesso em: 4 ago. 2017. 
GARRIDO, Elsa; PIMENTA, Selma Garrido; MOURA, Manoel Ariosvaldo de. A pesquisa colaborativa na escola como abordagem facilitadora para o desenvolvimento da profissão do professor. In. MARIN, Alda Junqueira (org.). Educação continuada: reflexões, alternativas. Campinas: Papirus, 2000. p. 89-112.

HELLER, Agnes. Sociología de la vida cotidiana. Segunda Edición. Barcelona: Ediciones Península, 1987.

JOSSO, Marie-Christine. Experiências de vida e formação. São Paulo: Cortez, 2004.

KOSIK, Karel. Dialética do concreto. Rio de Janeiro: Paz e Terra, 2002.

LAMPERT-SHEPEL, Elina. Aprendendo a refletir: domínio pelos professores e desenvolvimento de meios mediacionais e ferramentas psicológicas da prática reflexiva. Revista de Educação Cognitiva e Psicologia, v. 17, n. 3, 2018.

MARTINS, Lígia Márcia. Análise sócio-histórica do processo de personalização de professores. 340f. Tese (Doutorado em Educação) -Faculdade de Filosofia e Ciências de Marília, UNESP, Marília, 2001.

MARTINS, Lígia Márcia. As aparências enganam: divergências entre o materialismo históricodialético e as abordagens qualitativas de pesquisa. In: TULESKI, Silvana Calvo; CHAVES, Marta; LEITE, Hilusca Alves (orgs.). Materialismo Histórico-Dialético como fundamento da Teoria HistóricoCultural: método e metodologia da pesquisa. Maringá: EDUEM, 2015. p. 29-42.

MELLO, Suely Amaral. Linguagem, consciência e alienação: o óbvio como obstáculo ao desenvolvimento da consciência crítica. Marília: UNESP/Marilia Publicações, 2000.

MOURA, Maria da Glória Carvalho; FERREIRA, Adir Luz. A pesquisa colaborativa e a formação continuada do professor de educação de jovens e adultos: uma reflexão necessária, 2004. PDF Disponível em: http://www.ufpi.br/mesteduc/eventos/iiiencontro/gt1/pesquisa colaborativa Acesso em: 18 dez. 2018.

NAGEL, Lizia Helena. Do método ou de como pensar o pensamento. In: TULESKI, Silvana Calvo; CHAVES, Marta; LEITE, Hilusca Alves (orgs.). Materialismo Histórico-Dialético como fundamento da Teoria Histórico-Cultural: método e metodologia da pesquisa. Maringá: EDUEM, 2015, p. 19-28.

NORONHA, Olinda Maria. Pesquisa participante: respondo questões teórico-metodológicas. In: FAZENDA, Ivani. Metodologia da pesquisa educacional. 6. ed. São Paulo: Cortez, 2000. p. 137-143.

OLIVEIRA, Betty. A dialética do singular-particular-universal. In: ABRANTES, Angelo Antonio; SILVA, Nilma Renildes da; MARTINS, Sueli Terezinha Ferreira (orgs.). Método bistórico-social na psicologia. Petrópolis, Rio de Janeiro: Vozes, 2005. p. 25-51.

PASQUALINI, Juliana Campregher. Construção de princípios para a organização do ensino na educação infantil a partir da análise da prática do professor: relato de um percurso investigativo pautado no materialismo histórico-dialético. In: TULESKI, Silvana Calvo; CHAVES, Marta; LEITE, Hilusca Alves (orgs.). Materialismo Histórico-Dialético como fundamento da Teoria HistóricoCultural: método e metodologia da pesquisa. Maringá: EDUEM, 2015. p. 133-150.

PASQUALINI, Juliana Campregher; MARTINS, Lígia Márcia Dialética singular-particularuniversal: implicações do método materialista dialético para a psicologia. Psicol. Soc., Belo Horizonte, v. 27, n. 2, p. 362-371, ago. 2015. Disponível em: http://www.scielo.br/scielo.php?script=sci_arttext\&pid=S010271822015000200362\&lng=pt\&nrm=iso. Acesso $\quad$ em: 28 out. 2019. http://dx.doi.org/10.1590/1807-03102015v27n2p362.

PIMENTA, Selma. Garrido. Pesquisa-ação crítico-colaborativa: construindo seu significado a partir de experiências na formação e na atuação docente. In: PIMENTA, Selma Garrido; 
GHEDIN, Evandro; FRANCO, Maria Antonieta Santoro (orgs.). Pesquisa em educação: alternativas investigativas com objetos complexos. São Paulo: Loyola, 2006. p. 25-64.

PINTO, Álvaro Vieira. Ciência e existência. Rio de Janeiro: Paz e Terra, 1969.

RAUSCH, Rita Buzzi. Professor-pesquisador: concepções e práticas de mestres que atuam na educação básica. Revista Diálogo Educacional, Curitiba, v. 12, n. 37, 2012. p. 701-717.

RIGON, Algacir José; ASBAHR, Flávia da Silva Ferreira; MORETTI, Vanessa Dias. Sobre o processo de humanização. In: MOURA, Manoel Ariosvaldo de (org.). A atividade pedagógica na Teoria Histórico-Cultural. 2. ed., Campinas, São Paulo: Autores Associados, 2016. p. 15-50.

ROSSLER, João Henrique $\mathrm{O}$ desenvolvimento do psiquismo na vida cotidiana: aproximações entre a psicologia de Alexis N. Leontiev e a teoria da vida cotidiana de Agnes Heller. Cadernos CEDES, Campinas, v. 24, n. 62, abr. 2004. p. 100-116.

RUBINSTEIN, Sergei L. O problema da educação. In: LONGAREZI, Andrea Maturano; PUENTES, Roberto Valdés (orgs.). Tradutores: Ademir Damazio [et al.]. Ensino desenvolvimental: livro 1. Uberlândia, Minas Gerais: Ed. UFU, 2017. p. 123-130. (Coleção Biblioteca Psicopedagógica e Didática. Série Ensino Desenvolvimental; v. 4).

SÁNCHEZ VÁZQUEZ, Adolfo. Filosofia da práxis. 2. ed. Buenos Aires: Consejo Latinoamericano de Ciencias Sociales / Clasco: São Paulo: Expressão Popular, Brasil, 2011.

TOASSA, Gisele. Emoções e vivências em Vigotski: investigação para uma perspectiva históricocultural. 2009. 348f. Tese (Doutorado em Psicologia) - Instituto de Psicologia da Universidade de São Paulo, São Paulo, 2009.

THIOLLENT, Michel. Metodologia da pesquisa-ação. 15. ed. São Paulo: Cortez, 2007.

VIGOTSKI, Liev Semionovich. Quarta aula: o problema do meio na pedologia. Psicologia USP, São Paulo, 21 (4), p. 681-701, 2010.

VYGOTSKI, Liev Semiónovich. Obras Escogidas III. Madrid: A. Machado Libros, 2012.

VIGOTSKI, Liev Semionovich. Sete aulas de L. S. Vigotski sobre os fundamentos da pedologia. Organização [e tradução] Zoia Prestes, Elizabeth Tunes; tradução Cláudia da Costa Guimarães Santana. 1. ed. Rio de Janeiro: E-Papers, 2018.

VOLÓCHINOV, Valentin. Marxismo e filosofia da linguagem: problemas fundamentais do método sociológico na filosofia da linguagem. São Paulo: Editora 34, 2017.

ZEICHNER, Kenneth M. Uma agenda de pesquisa para a formação docente. Revista Brasileira de Pesquisa sobre Formação Docente, Belo Horizonte, v. 1, n. 1, ago./dez. 2009. p. 13-40.

Submetido em novembro de 2019. Aprovado em marco de 2020.

\section{Informações das autoras}

Isabel Cristina Fernandes Ferreira

Egressa do curso de Doutorado em Educação da Universidade Federal do Amazonas (Bolsista

Coordenação de Aperfeiçoamento de Pessoal de Nível Superior (CAPES)

E-mail: isacris29@gmail.com

ORCID: http://orcid.org/0000-0001-8470-9460

Link Lattes: http://lattes.cnpq.br/2527241349294798 
DOI: https://doi.org/10.12957/teias.2020.46653

Rita Esther Ferreira de Luna

Egressa do curso de Doutorado em Educação da Universidade Federal do Amazonas

E-mail: ritaestherluna10@gmail.com

ORCID: http://orcid.org/0000-0001-9815-6027

Link Lattes: http://lattes.cnpq.br/3807042671218885

Michelle de Freitas Bissoli

Docente da Faculdade de Educação da Universidade Federal do Amazonas

E-mail:mibissoli@ufam.edu.br

ORCID: http://orcid.org/0000-0002-2570-4392

Link Lattes: http://lattes.cnpq.br/8731672923902328 